\title{
Local organization for promoting energy efficiency—reform of local energy advice service in Sweden
}

\author{
Linnea Eriksson • Are Kjeang (i)
}

Received: 28 November 2019 / Accepted: 8 December 2020 / Published online: 28 December 2020

(C) The Author(s) 2020

\begin{abstract}
Homeowners are identified as a group in society that could change their energy behaviour towards greater energy efficiency and use of non-fossil fuels. External local energy advisors, who provide knowledge, motivation and service, can influence their decisions and thereby increase energy efficiency and dissemination of non-fossil fuels. In Sweden, the energy advice system has recently been reformed and this paper investigates this reform and analyses its early effects. The aim is to analyse how energy advisors manage the reform and how they work as middle actors to increase energy efficiency and non-fossil fuel use among homeowners. We use the theoretical framework of middle actors in the middle-out perspective together with the theory of institutional logics to analyse the case of the energy advisor reform. This qualitative analysis contributes to the discussion of energy advisors by focusing on the relevance of organizational structures
\end{abstract}

L. Eriksson

Department of Thematic Studies, Division of Technology and Social Change, Linköping University, SE-58183 Linköping, Sweden

e-mail: linnea.eriksson@vti.se

A. Kjeang $(\bowtie)$

Department of Engineering and Chemical Sciences, Karlstad University, SE-651 88 Karlstad, Sweden

e-mail: are.kjeang@kau.se

Present Address:

L. Eriksson

Swedish National Road and Transport Research Institute,

SE-58195 Linköping, Sweden and logics for their possibilities to influence homeowners' energy practices. The reform has introduced a governance and New Public Management logic that runs parallel with the former energy advice logic, guiding the advisors' work practice. The results show that the reform potentially has increased the energy advisors' ability to act as middle actors. However, there are organizational practices following the reform, which greatly constrain the advisors' abilities as middle actors. One conclusion is that the advisors are in need of more guidance from the Energy Agency to be able to perform more successful work.

Keywords Institutional logics · Energy advice · Energy efficiency $\cdot$ Municipality $\cdot$ Household, renewable energy

\section{Introduction}

To meet the challenges of climate change, a transition from fossil energy to renewable energy sources and increased energy efficiency are of great importance. The energy system spans the entire society; thus, changes must take place everywhere and by everyone. Homeowners are one group who could do much more both concerning energy-efficient renovations and everyday energy-related behaviour (Dietz et al., 2009; Murphy, 2014; Stieß and Dunkelberg, 2013; Wilson et al., 2015). Studies have shown that external actors (energy advisors) who can provide knowledge, motivation and service can influence homeowners' decisions and may lead to changes in behaviour that support 
energy efficiency and dissemination of non-fossil fuels (Dalenbäck et al., 2005; Darby, 1999; Mahapatra et al., 2011a; Salo et al., 2016). Such energy advisors are current in several European countries, provided as a public service or by businesses, or through a mixed model (Novikova et al., 2011; Ringel, 2018). In countries like Germany, Norway, Denmark and Finland, national or regional energy advising services have worked for several years (Mahapatra et al., 2011b). Norway and Denmark have well-designed websites for this purpose on a national basis, including activities on social media and telephone service. Locally, private consultants fulfil the services. In Denmark, the energy utilities also have an advising role in the national energy-efficiency policy (Enova, 2017; Tjørring, 2016).

In Sweden, the energy advisors have been a policy measure to enforce national energy policy since the 1970s (Kjeang et al., 2017). The energy advisors are financed by the national government but are provided and organized by the municipalities as 'local energy advisors' (LEA). This model has led to a major national variation between municipalities on how the service is provided and organized (SWECO, 2014). The government was not satisfied with the efficiency of the service (the money spent in relation to how many target groups potentially could be reached), resulting in a major institutional change in legislation, guidelines and the financial system for national support by autumn 2016. This paper will address this reform and analyse what early effects it has had for the local energy advice service and its potential future development.

The local energy advisors (LEAs) are considered possible middle actors (Parag and Janda, 2014) who are appointed to enforce national energy policy to homeowners within a local area. Their capacity as middle actors is influenced by the organizational practices at the municipality or municipalities where they are employed, but also by national policy and the Swedish Energy Agency (SEA) as a top actor. In addition, each energy advisor has agency as a middle actor depending on the personality and personal skills and ability to manage several institutional logics that serve as guidelines for the work.

The aim of this paper is to analyse how changes to institutional logics and organizational models influence the possibilities for LEAs to work as middle actors to increase energy efficiency and non-fossil fuel use among homeowners. We use the case of the Swedish reform of local energy advice service and the theoretical framework of middle actors in the middle-out perspective (Parag and Janda, 2014) together with the theory of institutional logics (Thornton et al., 2012). This qualitative analysis contributes to the discussion of energy advisors by focusing on the relevance of organizational structures and logics for their possibilities to influence homeowners' energy practices.

This first section continues with a short review of the literature on energy advice and how it works to influence homeowners' actions. Then the theoretical framework of middle actors and institutional logics is described, followed by the method. The second section describes the two current institutional logics and the municipal organizational models which are the results of the reform. In the third section, we analyse and discuss the LEAs' levels of agency and capacity as middle actors in different situations and make conclusions regarding what could be needed to improve the LEA system in Sweden.

\section{Initiatives regarding homeowners and efficient use of energy: background}

In this section, we present the background to the further discussion of different ways of approaching homeowners with a view to achieving energy upgrades in single-family houses. Research in this area is presented in an international context and connected to the concept of energy advising.

\section{Households}

In general, owners and household members in singlefamily houses do not focus on energy-related questions such as the heating system (Hamilton et al., 2019; Isaksson and Ellegård, 2015). There are, however, occasions in life when certain questions are raised and people are more receptive to information and more complex advising, for example, the birth of a child or moving into a new house (Klöckner, 2015; Rinkinen and Jalas, 2017). A window of the opportunity thus opens for energy advisors when homeowners are in these stages of life.

Research shows that households' daily habits, such as choice of room temperature, washing routines and lighting attention, vary greatly and result in large differences in total energy use in similar households (Gyberg and Palm, 2009; Lindén et al., 2006). Other researchers 
have noted that it is difficult to reach households through general information (Benders et al., 2006). According to Steg (2008), information must be tailored and specifically addressed to the type of homeowner or households you want to reach. The diversity of household types in detached houses is a big challenge, which is also emphasized by Gram-Hanssen et al. (2018). As Isaksson and Ellegård (2015) conclude, in order for information to be relevant and generate action, the message must be compatible with household members' own experiences and daily activities. However, there are also many examples of the benefits of households receiving feedback on various efforts made, for example, to streamline energy use (Burchell et al., 2016; Darby, 2006). The problem is that few households retain interest or commitment after a few months and most importantly after a year (Buchanan et al., 2015).

\section{Energy guidance}

Energy advising is one way of informing households regarding heating, insulation, electrical appliances, etc., but also regarding daily habits. This concept is used in many countries in different forms, and the guidance is normally provided by websites, telephone or e-mail (Novikova et al., 2011; Palm, 2010; Darby, 2003; Ringel, 2018). The most interactive way of advising is home visits, where the advisor and the homeowner can meet face-to-face. In Sweden, the organizational base is the municipalities, which makes it easier to include local arrangements like exhibitions and home visits. Palm (2010) examined the Swedish energy advisors' direct contacts with households and found that many advisors avoided giving individual household members direct advice on everyday behaviour. However, this sort of advice is challenging and indicates that advisors would benefit from communication skills training (Darby, 2003; Palm, 2010).

Local initiatives

Although private homeowner initiatives for energy renovations are few, municipalities around the world count on this possibility of energy efficiency in their climate action plans while also taking different initiatives (Gram-Hanssen et al., 2018). Research gives examples from a number of European countries. Martiskainen et al. (2018) analysed the 'Energy café' initiative in Great Britain. With some help from local authorities, these initiatives can be an important complement to official actions by combining social and climate policies. In Belgium and Netherland, local initiatives by authorities have been taken to reach homeowners in the local community by consultancy centres or 'popups' (Meijer et al., 2018). Gram-Hanssen et al. (2018) investigated the outcome of 12 local authorities to actively promote energy efficiency in single-family houses in Denmark. Stieß and Dunkelberg (2013) analysed German local investments 'social marketing campaigns'. The researchers recommended that local energy agencies go beyond their traditional roles, serving as an intermediary and multiplier among stakeholders and the local public.

These kinds of community initiatives also need a person with good knowledge and experience of energy and building areas. This key person can be a consultant, an energy advisor or someone representing the energy utility. Sebi et al. (2019) prefer an independent person to serve as an intermediary in the project. According to Ringel (2018), cooperation with other actors is needed. Based on German experiences, Ringel suggests more of a caretaking role from the advisor to succeed in the implementation: 'Offering independent energy advice is not enough. To succeed in the quickly changing energy service market, energy advisors will need to assume a "caretaker" role for their clients, covering advice and implementation of energy-saving solutions. This will only be possible through cooperation and collaboration with other actors' (Ringel 2018).

\section{National policies}

Sebi et al. (2019) compared the policies of the USA, Germany and France, stating that France places the highest demands on the redevelopment of detached houses with saving requirements of $50 \%$. Utility funding of energy efficiency is common in the USA and some states require retrofits before sale. Still, the three countries are struggling to encourage homeowners to expand their renovation thinking, from the present single-measure retrofits to comprehensive retrofits (Sebi et al., 2019). Based on the study of four countries in the EU that showed a willingness to go ahead, i.e., 'frontrunners', Murphy (2014) recommends tougher obligations, stronger incentives and more creative use of instruments.

An important area for more research and discussion is the need for more focus on the energy user, in this case, the 
homeowner and the occupants. How and when can these target groups be reached in a more efficient context?

\section{Theoretical framework: middle actors and institutional logics}

The LEAs are in this article regarded as 'middle actors' of the socio-technical energy system. We follow the argument made by Parag and Janda (2014) that middle actors are more than intermediaries between the top and bottom actors of the energy system since they have agency and as such 'they are active participants in the system, capable of creating (and sometimes preventing) change above, below and across other actors' (Parag and Janda, 2014: 103). Parag and Janda consider all actors to have both agency and capacity and that levels of the two must correlate to be high for the ability to make a change. Agency refers to the actors' willingness and capability to make their own free choices, and capacity refers to the actors' capability to perform the choices that he/she made. Both agency and capacity are interrelated with structural elements as physical and social constraints such as facilities, infrastructure, laws, institutional arrangements, contracts, norms and culture. Important for their potentially active role in the energy system change is that middle actors are in-between and that they have agency and capacity of their own to be able to improve the levels of agency and capacity of other actors.

According to Parag and Janda, the exact definition of what actors are in the middle depends on the sociotechnical system being analysed. Actors could also be both individual actors as well as organizational actors. In this article, the LEAs are regarded as possible middle actors since they act in-between the top actors (the national government which establishes national energy policy and the Energy Agency which is assigned to implement energy policy) and the bottom actors (the individual households which are one group of actors targeted by energy policy). According to the normative middle-out perspective on middle actors that Parag and Janda (2014) prescribe, the LEAs, as middle actors in the energy system, have the potential to make households change their energy use, as well as influence top actors and other middle actors to change. The focus in this article will be on this LEA potential to make a change among the group of households, by increasing both their agency and capacity to make changes. We focus on the structural elements of logics and organizational practices and how they disempower or empower the agency and capacity of LEAs acting as middle actors following the recent reform of the LEA service.

In this analysis, we use the institutional logics perspective to put a focus on the organizing principles of LEAs, which are a combination of 'material practices and symbolic constructions' (Friedland and Alford, 1991), thus logics that serve as guidelines in their work. How the logics work for the LEAs in general and how the individual LEA manages different logics are important for both their level of agency and capacity as middle actors.

The institutional logics perspective describes society as divided into mainly three different levels: macro, meso and micro. The macro level is the societal level, which comprises the key cornerstones of society, the institutional orders: family, community, religion, state, market, profession and corporation. The meso level contains organizations within institutional fields; a group of organizations that are similar or have a certain field in common and which could have certain organizational practices in common. The micro level consists of individuals, who are affected by institutional logics coming from the orders at the macro level and by institutional logics and organizational practices shaped on the meso level. The individual behaviour is shaped by these multiple logics, but the individual also possesses the agency to manage the logics (Greenwood and Suddaby, 2006; Holm, 1995; Seo and Creed, 2002; Thornton et al., 2012). We focus here on the micro level and how the institutional logics within the LEA organizational field influence the individual LEAs and how he or she manages the current different competing logics to either empower or disempower their agency and capacity as middle actors.

Our analysis of the LEAs' responses to the competing institutional logics will use the five responses suggested by Pache and Santos (2013): ignorance, compliance, defiance, combination and compartmentalization. Ignorance refers to an individual's lack of reaction towards an institutional logic. It is a non-conscious lack of response, which is due to a lack of awareness of the logic's influence. Compliance refers to an individual's full adoption of a logic on different degrees of consciousness. However, Pache and Santos (2013) argue that if there are several competing logics the individuals are forced to exercise some degree of agency when complying with one logic and not the others. Defiance refers to an individual's explicit rejection of a logic. A 
conscious act may vary in its degree of resistance, ranging from refusal to comply to active attempts to contradict or make the logic disappear. Combination refers to an individual's attempt to combine competing logics. To do that, they may use various strategies, for example selective coupling of elements drawn from each logic or development of their own norms, values or practices that synthesize the different logics. Compartmentalization refers to an individual's attempt to enact all competing logics, displaying compliance with one logic in one given context and another in another given context. This is a way for the individual to secure legitimacy in different contexts by complying to multiple logics, even though they may be incompatible (Pache and Santos, 2013).

Apart from the logics, the organizations within the LEA organizational field also affect the individual LEA's behaviour. They may do so by encouraging compliance with a certain logic or preventing compliance with a logic and instead emphasize other logics or organizational norms and practices (Pache and Santos, 2013). In the case of LEAs this is relevant concerning the top actor of the Energy Agency, which funds the LEA work, and the local authorities, municipalities, where the LEAs are mostly employed. The municipalities should not be understood as middle actors in the middle-out perspective; hence, they do not act in the energy system change within the LEA field. However, as employment organizations that receive the national funding for LEAs and organize them, their organizational practices are of relevance for the agency and capacity of the LEA as a middle actor.

\section{Method and material}

Local energy advice service in Sweden

In Sweden, the energy advice service started as part of the national energy policy to decrease the dependence on oil during the oil crises of the 1970s. The energy advisors were nationally funded but locally placed within municipalities throughout the country. During the 1970s and 1980s, the national funding was generous and with little national governing of the service. In 1986, the national government stopped funding the service and it turned out to be up to individual municipalities to decide whether they could afford and/or valued the service enough to fund it on their own (Kjeang, 1989).
In 1998, the national government started to fund local energy services again, following the same decentralized model from before: LEAs employed and situated at the municipalities, but nationally funded. In 2015, the LEA organization was complemented with a regional level (regional development leaders), who would coordinate the LEA work within their region and provide a regional network as well as continuing education within the energy field. The LEA organization is illustrated in Fig. 1.

The LEAs give advice to homeowners, small industry and businesses. The consultations have traditionally focused on energy use connected to the built environment. However, since 2008, the LEAs are also supposed to give advice about climate issues and climate friendly behaviour, which primarily means transport choices and behaviour. Since 1998, the number of LEAs has changed over the years. After the current reform, almost all municipalities (284 out of 290) still provide LEA service (Dahlman and Wistrand, SEA, 8th May 2017).

The local energy advice system in Sweden is, as described above, scattered and dependent on an overall national governance system, several different organizations and, due to the character of the LEA work, a number of individuals too. In accordance with this structure, the material which is the basis for analysis in this paper is derived from, on the one hand, official documents such as policy papers and evaluations produced by the national government, the Swedish Energy Agency, consultant reports and investigations. In addition, the material is also derived from in-depth interviews with representatives for all groups in the LEA system:

- Officials at the Energy Agency who have worked with the LEA system before and during the reform

- Regional development leaders (RDL) at 13 out of 15 regions

- Field-work notes and interviews with about 15 LEAs working in different municipalities across Sweden

The interviews were conducted during 2016 and 2017. All interviews have been semi-structured, meaning that questions and themes have been brought up in different orders, they have been reformulated when necessary, and different follow- 


\section{Swedish Energy Agency (SEA)}

\section{Regional Energy Office \\ 15 Regional development leaders (RDL)}

\section{Municipalities / Group of municipalities / Regional official organization \\ 185 Local energy advisors (LEA)}

Fig. 1 Energy advising organization in Sweden

up questions have been asked due to the conversation (Kvale and Brinkmann, 2009). The interviews with LEAs were intended to grasp their work reality and their experiences concerning what and how things influence their work. The interviews with the regional development leaders were intended to offer an overview of the LEA work in Sweden and, since most of them were conducted during the institutional change, they are also about the regional expectations and processes going on then. The group interview with officers at the Energy Agency had the purpose of getting more information about the reform from their perspective and asking about their understanding of several of the then-current solutions to the changes.

The study is based on a qualitative research tradition. Almost all interviews have been carefully transcribed or, if there are only notes, checked by the respondent. Most of the questions in the interviews have been worded such that the respondent should describe their understanding, views and thoughts about a certain matter. To interpret what the respondents actually mean in these statements, it has been important to take into account how something is said, in what situation, at what time and by which person at which position and background (Maxwell, 1992).

To bring order to statements and document abstracts, content analysis (Kvale and Brinkmann, 2009) has been used in a two-step process: first, the content has been sorted into different themes derived from the empirical knowledge of the LEA system and work; and second, these contents have been re-sorted into new themes derived from the theoretical framework of middle actors and institutional logics. The theoretical framework is thus inductively adopted; hence, it provided a possibility to understand the LEAs' situation and thereby draw conclusions from its consequences.

\section{Results}

The logics of the LEA organizational field

The two current logics within the LEA organizational field are influencing both the LEAs' agency and capacity to act as middle actors. The logic of energy advice has been established since the start of the LEA service, and the logic of governance and new public management have been more and more current during the recent 20 years, however, with more direct organizational consequences following the current reform in 2016.

\section{The institutional logic of energy advice}

The institutional logic of energy advice for the Swedish LEAs is not formalized in a national job description or something like it. Rather, the logic that guides the LEA work is based on two formalized principles and unanimous apprehensions of the Energy Agency, the LEAs themselves and other experts within the field. The first principle is that the LEAs should provide objective advice. This means objective in relation to other actors who sell energy devices, systems and solutions, but following current national energy policy: today with focus on energy-efficient solutions not based on fossil energy. This objectivity is however interpreted differently among individual LEAs, and some consider it difficult or even impossible to recommend best solutions and support households in their choice of energy devices and entrepreneurs, while others consider it part of the job. The second principle is that the LEAs are not allowed to work as consultants internally at the municipality, but only externally towards homeowners, local small industry and the rest of the public.

The unanimous apprehension is that LEAs must engage primarily in two forms of activity: consulting, 
and informational and outreach activities. The consulting activities require deep knowledge of the energy system and devices, and ability to give objective advice to all relevant questions. These activities are mainly done by phone but could also be done in person or through e-mail or other IT solutions. The informational and outreach activities require resources and engagement other than the basic consulting activities, for example marketing and social skills. These activities are driven by the LEA assignment to reach out to inform and increase knowledge among individuals, organizations and companies of energy-efficient and non-fossil action and behaviour, as well as the existence of the LEA role (Granath, 2012).

Following the need for deep energy system knowledge most LEAs are engineers, some specified within the energy field, but there are also others with different educational backgrounds such as teachers and environmental experts. Due to the diversity in educational background among the LEAs and the considered need for deep knowledge of the energy system to be able to give energy advice, the Energy Agency has had a common, mandatory training for those working as LEAs for the last 20 years. The education has created a baseline of knowledge in energy for all LEAs, but also an opportunity for newly recruited LEAs to meet others around the country. This has created a sense of an LEA community, important for those not having LEA colleagues in their municipality. In addition, before the reform, the Agency also used to arrange an annual conference for the LEAs to strengthen them in their role and provide them with skill updates.

This logic of energy advice has created an LEA identity, which is primarily based on deep energy knowledge and a sense of being a national profession, which is placed in different localities. The informational and outreach activities are also part of the logic of energy advice, even though communication skills have not been as important for LEA employment or work practice as energy knowledge. The logic of energy advice is not supporting a certain way of working as LEA; rather, the norm is that much of the LEA work and activities can be decided on by the individual based on personal expertise, experience and the characteristics of the local community.
The institutional logic of governance and new public management

Parallel to the logic of energy advice, the LEAs are also influenced by the logic of governance and New Public Management. This is a logic that has been current for the LEAs for some time but has been strengthened by the recent reform of the LEA funding and organization. This follows a common development, often described as New Public Management, where the public sector is organized based on ideas grounded in perceptions of socio-economic efficiency (Hood, 1991). In line with a governance structure for management, rather than a hierarchical government structure, the Energy Agency has since the mid-2000s organized their governing of the LEAs in the form of networks for information diffusion and support. These networks are regionally based.

There are about 15 regional energy offices throughout Sweden receiving financial support for coordinating LEAs within their regional area in a network for support and development of their work (Swedish Energy Agency, 2015). Often, this means that at least one person at the regional energy office serves as coordinator for the LEAs within the region. Their role is to organize network meetings for the LEAs to develop their skills, get to know each other and perhaps develop projects or working practices together. The regional coordinators should also work as mentors and support for the LEAs in their work. The regional networks have, in most regions, led to the arrangement of regular online telephone meetings and/or a common regional digital platform for LEAs to use for exchange of experiences, support and common regional campaigns to market the LEA service in the region. Since most of the LEAs are alone in their role in their municipality, the regional network often provides an opportunity for contact and support among others within the same profession. However, the regional networks work out differently; some have a close and well-functioning regional network that serves as a platform for collaboration concerning the organization of joint events and campaigns, while others have less collaboration through the regional network. The current reform has formalized the regional networks in the sense that today there are requirements for how many network meetings the regional coordinators have to organize to be funded and the coordinators are assigned to work as intermediaries between the Agency and the LEAs 
concerning sharing information and development of skills.

In addition to the network organization of the LEA field, the governing of LEAs has for about 15 years been guided by principles of new public management. This is in the sense that the LEA service has had quantified goals of the quantity of kWh energy to be reduced by their actions. Every funding period (which has varied between 3 years and 1 year), the LEAs have applied for their budget using goals of reduced $\mathrm{kWh}$, and then at the end of the period, they have written a quantified report where the LEAs have assessed their work in reduced $\mathrm{kWh}$. These reports have included the number of consultations given, however, not their quality or any follow-up if the advice provided has led to any real changes among the households.

The reform has further strengthened this logic of governance and new public management with the change of distribution principle of the financial support to LEAs. Before the reform, the distribution of funding was based on a rather equal geographical distribution among the municipalities. This meant that all municipalities that applied for funding could employ an LEA for at least $25 \%$ of full-time and the larger municipalities could apply for additional funding due to their larger population. The government, however, did not consider this geographical distribution an efficient use of financial resources. Therefore, the argument that the recent reform is based on, is that the LEA service could improve if the national financial support is distributed based on the size of relevant target groups, i.e., population and number of small industries and businesses, in each municipality (Swedish Energy Agency, 2015). The government argues that this distribution principle will improve the socio-economic efficiency of the LEA service (Swedish Government, 2016).

In the new support system, the support is separated into two categories: basic support, which every municipality that has an LEA service and fulfils the requirements is guaranteed to receive, and extended support, which is project-based and can be applied for by all municipalities that want to develop the LEA service further. The basic support requirements include that the LEA must participate in updating of skills and network meetings, that there must be a position established at the municipality/municipalities at least half-time, and that the LEA must participate in at least one national intervention project initiated by the Energy Agency (Swedish Government, 2016).
The mandatory national intervention projects aim to increase the common follow-up and aggregation of results from the LEA service on a national level (Swedish Energy Agency, 2017). They are launched with a clear project structure, support from a main project leader, goals for the LEAs to achieve, and a structure for report of results. The aim of the intervention projects is to strengthen the outreach part of the LEA service and thereby increase the effect and knowledge of it. This should be achieved through 'clearly assigned target groups, national coherent projects and a clear message' (Swedish Energy Agency, 2017). The intervention projects are established by the Energy Agency, and they prescribe how each LEA should work with an issue. The results to be reported are easily quantified measures such as number of households given advice or the number of events the LEA has organized to provide information about the matter.

The extended support should be for those LEAs who have a specific idea for a project which is not possible to perform within the basic financial support (Dahlman and Wistrand, SEA, 8th May 2017). It is prescribed that the project must aim for stimulation of cooperation between municipalities or projects that focus on specific local conditions for the LEA work (Swedish Government, 2016). To get the extended support, the LEAs must apply for it and the Energy Agency will evaluate the applications and decide which projects will get funding. The Energy Agency considers the extended support a way for them to make room for testing new ideas of how to spread the message of energy efficiency and a way to connect the LEA service to the local context (Dahlman and Wistrand, SEA, May 8, 2017).

Municipalities - organizational practices

Since the LEAs are employed by one or more municipalities the LEA's capacity as a middle actor is influenced by the organizational practice of the specific municipality in which the LEA works. Due to different characteristics and preconditions the organizational practices differ greatly among the municipalities, whether the municipality is small or large in terms of both territory and inhabitants, how it is organized, the level of engagement in LEA work by the manager, where the LEA is placed within the municipality, if the LEA has good connections within the municipality, if the municipality is rich or poor, and what issues are politically prioritized. These organizational practices have also 
been greatly changed due to the current reform of the funding system.

\section{Models of LEA organization}

Since the LEA service is mostly nationally funded, the support system is of importance to how the municipalities organize their LEA service. In the former financial support system of LEAs, all municipalities, regardless of population, were guaranteed a support that covered a 25\% LEA position. Municipalities with a population of more than 30,000 could apply for additional funds, with amounts depending on the number of inhabitants. Some municipalities got funding that covered full LEA employment and others half-time LEA employment. Depending on the financial situation and the interest at the municipality, some municipalities funded a full-time or part-time LEA position on their own or combined a position as LEA with another position at the municipality.

The establishment of target groups as the principle for basic support has had major consequences on the financial support for each municipality. Today, the lowest amount of funding is set at SEK 50,000 and the largest amount at SEK 2 million (Swedish Energy Agency, 2016; Swedish Government, 2016). The current lowest amount of funding does not cover a halftime LEA position, which is one of the requirements to be able to apply for basic support. Therefore, because of the reform, numerous municipalities have had to form clusters of several municipalities to be able to uphold $50 \%$ national financial support for the LEA service. Some municipalities have solved the situation by compensating for the lack of national financial support with municipal funds to be able to keep the LEA role in the municipality (Dahlman and Wistrand, SEA, 8th May 2017).

Since the financial reform, we have found that the municipalities have organized the LEA service primarily according to four different models. Which model each municipality has chosen depends on the amount of funding the municipality gets, the financial situation of the municipality and the level of engagement in LEA issues. Here follows a description of each model:

\section{One LEA at one municipality}

Working only as LEA, part-time to full-time.

\section{Shared employment: part-time LEA, part-time another role}

LEAs who have a shared position are part-time LEAs and part-time in another role at the municipality. Examples of common combinations are LEAs who also are building permit officers, environmental inspectors, consumer guides or environmental strategists. The first two roles are mandatory for the municipality to have, and it is part of the municipal mandate to exercise authority concerning these issues. The last role as environmental strategist is often a way for the municipality to also utilize the expert knowledge of the LEA for internal work with energy and environmental issues within the municipal organization.

\section{Group of LEAs at one municipality}

This model is mostly exercised by larger municipalities with the opportunity to have two or more people working as LEAs in the municipality. The working process may be different from the individual situation in the first two categories; each LEA in the group may have less knowledge of and responsibility for the work since the group often has a manager, and it is possible to divide the work between LEAs with different expertise. At the municipality, the LEAs become a unit, which might make it easier to be more known within the municipality. Following the current reform, there are more municipalities (about 20) that receive more funding and have the possibility to form a group of LEAs (Dahlman and Wistrand SEA, May 8, 2017; personal communication RDL).

\section{One LEA for a cluster (group) of municipalities}

Several municipalities collaborate to provide an LEA service, half-time to full-time, since many receive less funding because of the reform. Today, clusters of municipalities for LEA service are common throughout the entire country. The number of municipalities within a cluster varies from two up to about eight. The clusters are differently organized, but often the LEA has one 'home' municipality where he or she is employed and has a workplace. The relationship with the other municipalities in the cluster is often regulated in a contract: some LEAs visit all the other municipalities a certain 
day and time per week or month, while some are only obliged to uphold the consulting activity by phone in many of the participating municipalities and do all outreach activities in their 'home' municipality. Everything between these two extremes occurs.

In some cases, a larger municipality has formed clusters with smaller neighbouring municipalities for the LEA service. We have indications that these clusters have the character of charity work; that the larger municipality with more resources helps or offers the smaller municipality more service than their financial resources can justify.

The municipal organization and position

In addition to the organizational practices that are results of the financial funding, we have also found that the engagement and incorporation of the LEA role in the municipal organization differs and is important for the capacity of the LEA.

In the ordinary municipal work, there are a few areas where the LEA service clearly connects to it and it would be beneficial for the LEA to collaborate with the officers within these areas. In the case of homeowners, it is primarily the building permit office which is of interest for LEA collaboration. This is the part of the municipality that homeowners must be in contact with while planning for building new homes or major renovations to their current homes. Collaboration with these officers may thereby provide the LEA with contacts among homeowners who may need advice about how to manage energy issues. There are examples of LEAs that work in collaboration with this part of the municipality, but most do not. The argument for why this does not happen among LEAs varies from that the building permit officers do not have time or interest to collaborate to that the building permit process is too late in the building process for most homeowners, for which reason there is no need to have such a collaboration.

Another reason for this lack of collaboration within the municipality could be that a major part of our respondents describe the LEA as somewhat apart from or even foreign to the municipal organization in the sense that few or no one (not even the manager) knows or cares about their work and objectives. This often means that the LEA service becomes a parallel activity, separate from the original municipal work activities. In other cases, the LEA is well incorporated into the municipal organization, by policy, engaged managers and/or politicians and/or by shared employment with a role that half-time is part of the municipality's ordinary work. In these latter cases, however, the organizational identity such as environmental inspector or building permit officer might be stronger and overshadow the role and identity as LEA, depending either on the priorities of managers, politicians and others or by the individual LEA.

Another aspect of the LEA's capacity to work as a middle actor is the position of the municipality and/or the LEA in the local community. This is important for the LEA service, since much of it depends on contacts with citizens and knowledge of the service among the population. In addition, good contacts in the local community among other actors important for homeowners in their daily life, for renovating or building their home and for buying a new home are also important for the LEA to have. The LEAs may both influence these actors' actions towards homeowners directly as well as involve them in activities that may change both their and the homeowners' approach towards energy use. A municipality with legitimacy and popularity in the local community may provide good preconditions for all these contacts. The knowledge of LEA service is better in municipalities with smaller populations than in the urban areas (SCB, 2015), which indicates that a small municipality, in terms of population, better provides such preconditions than a larger municipality. Another aspect of this is that the individual LEA may be well connected in the local community outside the municipality irrespective of his/her position at the municipality. The LEA is then well known in the community and upholds a strong local identity, which means that the LEA has many local contacts and may easily arrange outreach and network activities.

\section{Summary and analysis of findings}

Level of agency as middle actors

The LEA role has always been mainly up to the individual LEA concerning how to organize and perform the work, as long as they follow the principle of objective advice and only work as advisors to the municipal population and businesses. The LEAs' agency as middle actors is thereby greatly dependent on their personal character and skills. Some LEAs are better working with consulting activities due to deep energy knowledge 
while some LEAs are better at working with outreach and informational activities, due to that sort of skills. Some LEAs lean more towards one of the extremes and others are a combination. Their personality and skills influence how they perform the work; some otherwise successful ways to work may not be selected since the individual LEA feels it is not for him/her. Different approaches also work out differently for different LEAs.

One example is the different interpretations of the objectivity principle - one of the major pillars of the logic of advice - where some LEAs interpret it as an obstacle to far-reaching supervision of homeowners refurbishing their homes, while other LEAs do not see it as an obstacle and engage in far-reaching supervision of homeowners. The engagement, knowledge and interpretations are made by the individuals in the LEA role, and work is thus of major importance if their agency as middle actors is high or low.

The reform has not directly changed the influence of personal skills on the LEA service. A LEA who succeeded in reaching out to the local community and was known among the target groups before the reform could often use the changes of extended support and intervention projects to do the same as before or more after the reform. These LEAs seem to have high agency since they manage to combine (Pache and Santos, 2013) the two current logics in their work. They incorporate the requirement of aggregated results with their usual advisory activities which they know work in their community and extend their activities where it seems necessary. Some of these LEAs also use their skills at writing grant applications for projects to try new ideas to be financed by extended support. However, these LEAs probably also had high agency before the reform and it might be one reason why their combination of the competing logics seems to work and empowers them with high agency.

LEAs with major professional skills within the energy area, but rather limited skills in reaching out to target groups, could before the reform depend only on the contacts made by citizens in the need for advice. However, after the reform, these LEAs must work on a minimum scale with outreach activities within the intervention projects. They thereby comply with the logic of governance and New Public Management in the projects with a specific demand for that, but otherwise, they continue to wait for contact to give advice. If the intervention projects are successfully planned, this might result in more calls for advice and thus increasing influence as middle actors. However, if not there is a risk that these LEAs become less known and get fewer opportunities to give advice. Few of these LEAs thus use their agency to try new ways to reach and support homeowners to change their energy practices, apart from what they must do. These LEAs try to enact both current logics and use them for certain situations, in line with Pache and Santos' (2013) concept of compartmentalization. However, the compartmentalization of these LEAs is non-active in the sense that they follow the logics restricted to what they must do. Their agency as middle actors should therefore be considered as rather low.

The analysis implies that the level of agency is higher for the LEAs that manage to combine the two logics to support their work and that the agency is lower for those who passively comply with both logics. However, according to Parag and Janda (2014), high level of agency is not enough for an actor to be a middle actor. The level of capacity is also of major importance.

Level of capacity as middle actors

The level of capacity of the LEA to work as a middle actor is much influenced by the organizational practices and more specifically the structure of funding and thus the models of municipal organization that have followed the reform. The organizational practices may encourage the LEA to combine the current logics or encourage compliance with only one logic or obstruct the LEA to combine or comply with the logics at all and emphasize other norms and practices instead (Pache and Santos, 2013). This is influential for the LEA level of capacity as middle actors.

First, in the case of LEAs working full time at one municipality, his/her capacity is mainly influenced by the priority of LEA-related policy and work within the municipality and the engagement of the organization and manager. A municipal organization which is engaged in LEA-related issues could support and even enforce a combination of the logic of energy advice and the logic of governance and New Public Management. This is because the LEA has the ability to manage his/her own work within the framework of the municipality and has enough resources to be able to use the new funding system to develop the work, by applying for extended support. A municipality that understands the LEA work also supports internal networks between different professions to make the LEA improve contacts 
and advice opportunities with target groups. The LEA capacity as middle actor is thus empowered by the organizational practices in these cases.

Second, in the case of LEAs working half-time in one municipality, the capacity to work as middle actor may be more constrained. An LEA with a shared position could rely on an extended network of contacts to perform more outreach and networking. There are examples of LEAs also working as building permit officers, who improve the LEA contacts with homeowners using that position. There might, however, be difficulties in being able to concentrate on the LEA work if the other part of the employment takes much time and is more prioritized by managers, the municipality or the LEA her/himself. In summary, the half-time position as LEA and another role, both have the possibility to strengthen the LEA's capacity to combine the logics, but also involves a risk that the LEA capacity becomes constrained due to more focus on the other position.

Third, in the case of clusters, the capacity to act as middle actor is constrained. The size of the territory is one constraining factor. The larger the territory to cover, the longer the trips for outreach activities, and consulting activities are by means other than phone and ICT. This could make outreach and networking activities difficult to execute since they possibly either cost more than the budget or less time can be spent on the activities when the budget must be used for transport. Another constraining factor is that the LEAs often lack connection to the local community in several of the municipalities since they spend little or no time there. This constrains the ability of the LEA to organize events and spread LEA knowledge among target groups in these municipalities. In addition, the organization of clusters and how the municipal anchoring of the LEA work is performed influences the level of LEA capacity. If this work is up to the LEA, it takes time from the core activities and starts to become complicated when working for only two municipalities. However, several of the clusters have organized the anchor work using contact persons at each of the other municipalities to facilitate the anchoring of LEA work. In these cases, it is less of a problem.

As described, there are several constraining factors that diminish the capacity for LEAs in clusters of municipalities. In addition, several of these LEAs are employed half-time as LEA. Even if the individual LEA has a high agency to combine and use the two logics to improve the work, this agency must be considered constrained by a lower capacity, when it means that the LEA must spend time going things other than the core work. Thereby, a passive compliance with the logics is the only way for the LEA to manage the work. The cluster organization for the LEA work should thus be considered as a disempowering organizational practice for the LEA capacity.

Fourth, when the LEA service is a group of at least two, they have other opportunities than working on their own. They might divide the work between them depending on their personality and skills: either each person specializes in some issues, or else they focus differently on outreach work on the one hand and consulting work on the other. This division of activities may improve their common agency as middle actors. In addition, a group would have more possibilities to become known among the target groups through collaborations with other organizations, companies and departments within the municipality. Since a group has the possibility to be more visible within the municipality than one person, this suggests that the internal work could be much easier. This organizational model thus provides the LEAs with preconditions to combine the two logics in improving their work and their level of capacity. If the resources are used to enhance each person's agency, it may also improve the agency of the LEAs. A high level of agency and capacity imply, according to Parag and Janda (2014), that these LEAs are working as middle actors supporting homeowners in their energy practice change.

However, there are other aspects of these municipalities with bigger populations that may constrain the LEA capacity. First, several of our informants experience that it is much harder to reach out to the target groups in more densely populated areas, since there is a lot of other information and events going on in the local community and this works to constrain their capacity. Second, we have seen examples of groups of LEAs that comply with the different logics in certain situations and only target the role as consultants with little outreach work and networking. This may have negative impact on their capacity as middle actors in the long run, since they risk becoming less known among homeowners. A group of LEAs thus increases the probability that the logics are combined and the capacity as middle actor is high, but there is no guarantee for that.

Another aspect which influences the level of capacity of LEAs as middle actors is the actions of the top actor, in this case the Energy Agency. The Agency's 
governance of the LEA system is, as described, based primarily on regional networks in supporting the single LEAs in their everyday work, national intervention projects led by someone external to the Agency and an aggregated system for reports of the LEA results. The top actor supports the LEA work in detail concerning the intervention projects, but in the rest of the work, there is little support concerning how to perform the LEA work. The regional networks may offer support concerning these matters, but then what is emphasized is dependent on the regional network and its leader. The same goes for recruitment of LEAs where it is entirely up to the municipalities who they recruit. In some cases, the regional network serves as support, but not always. The Agency is thus neither promoting nor discouraging the LEA capacity, but rather leaves the support of the LEA role to the regional networks, the municipalities and the LEAs themselves.

\section{Concluding discussion}

The LEAs are situated and thought of as middle actors in the energy system, but are they really working as middle actors? Do they have a high agency and high capacity to empower the homeowners' agency and capacity to make changes to their energy system and behaviour?

We have argued that the reform of the LEA system has resulted in two competing logics that guide the LEA work: the logic of advice and the logic of governance and New Public Management. The former consists of norms and practices of the LEA work current for a long time and the latter consists of the norms, rules and practices which have followed the reform, although some were current before. The logics perspective has given the opportunity to consider all aspects of the reform, not only the formal legislation. However, the logics perspective may be constrained in the sense that other aspects which do not correlate with the logics are not considered in the analysis.

From our analysis of how the LEAs manage the two different logics, using the perspective of Pache and Santos (2013), we suggest that the LEAs that manage to combine the logics in their work, due to high agency and capacity, are most likely to work as successful middle actors. If LEAs instead comply with each logic in certain situations, i.e., following the formal restrictions, what Pache and
Santos call decompartmentalization, they are not as likely to be successful middle actors.

A combination of the logics means in practice that the LEA has deep energy skills and marketing skills to be able to both give far-reaching support to advice seekers and to work with outreach activities and networking to be more known in the community. The outreach activities are based on thorough analysis of the most important target groups to reach. The LEA also uses the position within the municipal organization to reach target groups through cooperation with other professions and other possible contact points with target groups at the municipality. In this way, the LEA may use his/her network, contacts and analysis to incorporate national intervention projects and other activities in a model for action which includes certain ways to give energy advice.

The success of these LEAs as middle actors in the energy system is in our study only based on the LEAs' experiences and surrounding actors' apprehensions of the work. However, previous research on energy advice for homeowners has shown for example that networking activities in the local community provides a necessary base for the advisor to support the homeowner in major renovations (Gram-Hanssen et al., 2018; Ringel, 2018). Other researchers argue that tailored advice to certain groups of homeowners, i.e., target group analysis on which to base advising activities, may contribute to change daily household activities, which is important for energy change (Steg, 2008). The LEAs that combine the logics thus seem to work in line with these arguments, which is why they may be interpreted to be what Parag and Janda (2014) call middle actors. Our analysis show that since the reform, full-time LEAs at one municipality and a group of LEAs have the best preconditions to act as middle actors.

A decompartmentalisation of the logics means, on the other hand, that the LEA only depends on energy skills to give advice, waiting for people to take contact. Since the reform prescribes participation in networking and outreach activities these LEAs take part in these activities, but they do not incorporate them in their work and thereby do not use them to develop their ways of working with energy advice. In these cases, successful intervention projects may empower the LEAs as middle actors, while less successful ones may not. The Energy Agency thus, as initiator of the projects, has an opportunity to improve these LEAs as middle actors. Our analysis shows that the decompartmentalisation of 
logics is not only due to LEAs' agency, but also their capacity. The clusters of municipalities with common LEA service, which are a result of the reform, are shown to act as constraining for the LEA to combine logics and rather force them to comply with the logics in a passive way. The organization of the clusters may make the intervention projects only available in one of the municipalities and further constrain the LEA ability to work as middle actor.

In summary, the reform of the Swedish LEA system has provided the LEAs with some new tools that may improve their work as middle actors. However, it has also resulted in organizational models which either improve them as middle actors or instead constrain the LEAs as middle actors. This is true for the first year of the reform. What happens in the longer run would be important for research to follow.

As shown, the LEA's own agency has much impact on the work performed and if every LEA will work with issues and in ways that we know from research works, the capacity to do so must improve. We would argue on the basis of our results that one way to do that is the development of a national working description of what a LEA is and should do, in order for the Energy Agency to help the municipalities to recruit LEAs that are well equipped to have high agency to perform the abovediscussed work. Furthermore, the Energy Agency must be clear in how far-reaching the LEAs can be and support them with a clear mandate to engage in homeowners' major refurbishments through networking with the surrounding community (Murphy, 2014; Ringel, 2018). In addition, the municipality is an important arena for the LEA to network within to reach homeowners in need of advice (Gram-Hanssen et al., 2018; Sebi et al., 2019). Organizational practices within the municipalities may facilitate this work, which indicates that there is a need for directives towards the municipal organizations to better collaborate with the LEA work.

The Swedish case of reform of LEAs shows the relevance of how the structure that support, guide and rule the actors is organized for middle actors being empowered or not in their role as middle actors in the transition of the energy system. Some of the results or the combination of the theoretical framework may be useful, not only for improving energy advice services in other countries, but also in other technical systems which transition may partly depend on middle actors and their position. New Public Management is a common logic that permeate western democracies and their bureaucracies and, even if the logic we define in the LEA case is not covering all aspects of NPM, it gives an idea of how NPM logic may be used to improve the work of middle actors and also elucidate its constrains.

The results from this Swedish case of local energy advice service show both how such a service may be organized and what problems and possibilities a certain way to organize bring to middle acting.

Acknowledgements The authors would like to thank the Swedish Energy Agency for funding the research and all of you who have participated in the study and made it possible. Thanks also to professor Jenny Palm, Lisa Hansson and colleagues at the Thematic Department, Linköping University, for valuable comments. We are also much grateful for comments received by two anonymous reviewers. These comments helped us improve the paper.

Funding Open Access funding provided by Karlstad University.

\section{Compliance with ethical standards}

Conflict of interest The authors declare that they have no known competing financial interests or personal relationships that could have appeared to influence the work reported in this paper.

Open Access This article is licensed under a Creative Commons Attribution 4.0 International License, which permits use, sharing, adaptation, distribution and reproduction in any medium or format, as long as you give appropriate credit to the original author(s) and the source, provide a link to the Creative Commons licence, and indicate if changes were made. The images or other third party material in this article are included in the article's Creative Commons licence, unless indicated otherwise in a credit line to the material. If material is not included in the article's Creative Commons licence and your intended use is not permitted by statutory regulation or exceeds the permitted use, you will need to obtain permission directly from the copyright holder. To view a copy of this licence, visit http://creativecommons.org/licenses/by/4.0/.

\section{References}

Benders, R. M., Kok, R., Moll, H. C., Wiersma, G., \& Noorman, K. J. (2006). New approaches for household energy conservation-In search of personal household energy budgets and energy reduction options. Energy Policy, 34(18), 3612-3622.

Buchanan, K., Russo, R., \& Anderson, B. (2015). The question of energy reduction: The problem(s) with feedback. Energy Policy, 77, 89-96. https://doi.org/10.1016/j. enpol.2014.12.008. 
Burchell, K., Rettie, R., \& Roberts, T. C. (2016). Householder engagement with energy consumption feedback: The role of community action and communications. Energy Policy, 88, 178-186. https://doi.org/10.1016/j.enpol.2015.10.019.

Dalenbäck, J.-O., Göransson, A., Jagemar, L., Nilsson, A., Olsson, D., \& Pettersson, B. (2005). Åtgärder för ökad energieffektivsering $i$ bebyggelse. Gothenburg: Chalmers University of Technology.

Darby, S. (1999). Energy advice-what is it worth. https://www. eceee.org/library/conference_proceedings/eceee_Summer_ Studies/1999/. Accessed 1 Aug 2019.

Darby, S. (2003). Making sense of energy advice. Summer Study Proceedings. https://www.eceee.org/library/conference proceedings/eceee_Summer_Studies/2003/Panel_6/6157 darby/. Accessed 1 March 2020.

Darby, S. (2006). The effectiveness of feedback on energy consumption: A review for DEFRA of the literature on metering, billing and direct displays (Vol. 486). Oxford: Environmental Change Institute, University of Oxford.

Dietz, T., Gardner, G. T., Gilligan, J., Stern, P. C., \& Vandenbergh, M. P. (2009). Household actions can provide a behavioral wedge to rapidly reduce US carbon emissions. Proceedings of the National Academy of Sciences, 106(44), 18452-18456.

Enova (2017). Årsrapport 2016. https://www.enova.no/omenova/kampanjer/arsrapport-2016/. Accessed 1 Aug 2019.

Friedland, R., \& Alford, R. R. (1991). Bringing society back in: Symbols, practices and institutional contradictions. In W. Powell \& P. DiMaggio (Eds.), The new institutionalism in organisational analysis (pp. 232-267). Chicago: University of Chicago Press.

Gram-Hanssen, K., Jensen, J. O., \& Friis, F. (2018). Local strategies to promote energy retrofitting of single-family houses. Energy Efficiency, 11(8), 1955-1970.

Granath, M. (2012). Kan professioner organiseras fram?: En fallstudie av den kommunala energi-och klimatrådgivningen. Linköping: Linköping University Electronic Press.

Greenwood, R., \& Suddaby, R. (2006). Institutional entrepreneurship in mature fields: The big five accounting firms. Academy of Management Journal, 49(1), 27-48. https://doi. org/10.5465/amj.2006.20785498.

Gyberg, P., \& Palm, J. (2009). Influencing households' energy behaviour-How is this done and on what premises? Energy Policy, 37(7), 2807-2813. https://doi.org/10.1016/j. enpol.2009.03.043.

Hamilton, J., Hogan, B., Lucas, K., \& Mayne, R. (2019). Conversations about conservation? Using social network analysis to understand energy practices. Energy Research \& Social Science, 49, 180-191.

Holm, P. (1995). The dynamics of institutionalization: Transformation processes in Norwegian fisheries. Administrative Science Quarterly, 40(3), 398-422. https://doi.org/10.2307/2393791.

Hood, C. (1991). A public management for all seasons? Public Administration, 69(1), 3-19. https://doi.org/10.1111/j.14679299.1991.tb00779.x.

Isaksson, C., \& Ellegård, K. (2015). Anchoring energy efficiency information in households' everyday projects: Peoples' understanding of renewable heating systems. Energy Efficiency, 8(2), 353-364. https://doi.org/10.1007/s12053-014-9299-x.
Kjeang, A. E. (1989). God energirådgivning på 90-talet. Stockholm: Föreningen Sveriges energirådgivare.

Kjeang, A. E., Palm, J., \& Venkatesh, G. (2017). Local energy advising in Sweden: Historical development and lessons for future policy-making. Sustainability, 9(12), 2275. https://doi. org/10.3390/su9122275.

Klöckner, C. A. (2015). The psychology of pro-environmental communication. Beyond Standard Information Strategies: Palgrave MacMillan.

Kvale, S., \& Brinkmann, S. (2009). Learning the craft of qualitative research interviewing. Los Angeles: Sage Publications.

Lindén, A.-L., Carlsson-Kanyama, A., \& Eriksson, B. (2006). Efficient and inefficient aspects of residential energy behaviour: What are the policy instruments for change? Energy Policy, 34(14), 1918-1927. https://doi.org/10.1016/j. enpol.2005.01.015.

Mahapatra, K., Nair, G., \& Gustavsson, L. (2011a). Energy advice service as perceived by Swedish homeowners. International Journal of Consumer Studies, 35(1), 104-111. https://oi. org/10.1111/j.1470-6431.2010.00924.x.

Mahapatra, K., Nair, G., \& Gustavsson, L. (2011b). Swedish energy advisers' perceptions regarding and suggestions for fulfilling homeowner expectations. Special Section: Renewable Energy Policy and Development, 39(7), 42644273. https://doi.org/10.1016/j.enpol.2011.04.043.

Martiskainen, M., Heiskanen, E., \& Speciale, G. (2018). Community energy initiatives to alleviate fuel poverty: The material politics of Energy Cafés. Local Environment, 23(1), 20-35.

Maxwell, J. (1992). Understanding and validity in qualitative research. Harvard Educational Review, 62(3), 279-301. https://doi.org/10.17763/haer.62.3.8323320856251826.

Meijer, F., Straub, A., \& Mlecnic, E. (2018). Consultancy centres and pop-ups as local authority policy instruments to stimulate adoption of energy efficiency by homeowners. Sustainability, 10(8), 2734.

Murphy, L. (2014). The policy instruments of European frontrunners: Effective for saving energy in existing dwellings? Energy Efficiency, 7(2), 285-301.

Novikova, A., Amecke, H., Neuhoff, K., Stelmakh, K., Kiss, B., Rohde, C., et al. (2011). Information tools for energy demand reduction in existing residential buildings: CPI report. Lund: Lund University.

Pache, A.-C. \& Santos, F. (2013). Embedded in Hybrid Contexts: How Individuals in Organizations Respond to Competing Institutional Logics, IN. Lounsbury, M. and Boxenbaum, E. (Ed.) Institutional Logics in Action, Part B (Research in the Sociology of Organizations, Part B). Emerald Group Publishing Limited, 39, 3-35. https://doi.org/10.1108 /S0733-558X(2013)0039AB014

Palm, J. (2010). The public-private divide in household behavior: How far into home can energy guidance reach? Energy Policy, 38(6), 2858-2864. https://doi.org/10.1016/j. enpol.2010.01.018.

Parag, Y., \& Janda, K. B. (2014). More than filler: Middle actors and socio-technical change in the energy system from the "middle-out". Energy Research \& Social Science, 3, 102112.

Ringel, M. (2018). Energy advice in Germany: A market actors' perspective. International Journal of Energy Sector 
Management, 12(4), 656-674. https://doi.org/10.1108 /IJESM-04-2018-0002.

Rinkinen, J., \& Jalas, M. (2017). Moving home: Houses, new occupants and the formation of heating practices. Building Research and Information, 45(3), 293-302.

Salo, M., Nissinen, A., Lilja, R., Olkanen, E., O'Neill, M., \& Uotinen, M. (2016). Tailored advice and services to enhance sustainable household consumption in Finland. Journal of Cleaner Production, 121, 200-207. https://doi.org/10.1016/j. jclepro.2016.01.092.

Sebi, C., Nadel, S., Schlomann, B., \& Steinbach, J. (2019). Policy strategies for achieving large long-term savings from retrofitting existing buildings. Energy Efficiency, 12(1), 89105.

Seo, M.-G., \& Creed, W. E. D. (2002). Institutional contradictions, praxis, and institutional change: A dialectical perspective. Academy of Management Review, 27(2), 222-247. https://doi.org/10.5465/amr.2002.6588004.

Statistics Sweden (2015). Allmänhetens energieffektivisering och kännedom om energi- och klimatrådgivare. http://www. e $\mathrm{n}$ e $\mathrm{r} \mathrm{g}$ i $\mathrm{m} \mathrm{y} \mathrm{n}$ d i g h e $\mathrm{t}$ e $\mathrm{n}$. se/globalassets/energieffektivisering/program-ochuppdrag/ekr/bilaga2-scb.pdf. Accessed 1 Aug 2019.

Steg, L. (2008). Promoting household energy conservation. Energy Policy, 36(12), 4449-4453. https://doi.org/10.1016 /j.enpol.2008.09.027.

Stieß, I., \& Dunkelberg, E. (2013). Objectives, barriers and occasions for energy efficient refurbishment by private homeowners. Journal of Cleaner Production, 48, 250-259. https://doi.org/10.1016/j.jclepro.2012.09.041.

SWECO. (2014). Styrmedels förutsättningar att styra mot ökad energieffektivisering - en utvärdering av 24 styrmedel. Stockholm: Näringsdepartementet.
Swedish Energy Agency (2015). Översyn av den kommunala energi- och klimatrådgivning. https://www.regeringen. $\mathrm{se} /$ contentassets/c88fb785dcbe4c34b8905372d26a341 f/energimyndighetens-rapport-oversyn-av-den-kommunalaenergi-ochklimatradgivningen.pdf. Accessed 1 Aug 2019.

Swedish Energy Agency (2016). Statens energimyndighets föreskrifter om bidrag till kommunal energi- och klimatrådgivning. STEMFS 2016:3. https://www. en ergimyndigheten.se/globalas sets/o moss/foreskrifter/2016_3.pdf. Accessed 1 Aug 2019.

Swedish Energy Agency (2017). Projektplan insatsprojekt sol. http://www.energimyndigheten.se/soksida/?query= om+insatsprojektet+2017.pptx. Accessed 1 Aug 2019.

Swedish Government. (2016). Förordning om bidrag till komunal energi- och klimatrådgivning. Ordinance, 2016, 385.

Thornton, P. H., Ocasio, W., \& Lounsbury, M. (2012). The institutional logics perspective: A new approach to culture, structure, and process. Oxford: Oxford University Press.

Tjørring, L. (2016). We forgot half of the population! The significance of gender in Danish energy renovation projects. Energy Research \& Social Science, 22, 115-124. https://doi.org/10.1016/j.erss.2016.08.008.

Wilson, C., Crane, L., \& Chryssochoidis, G. (2015). Why do homeowners renovate energy efficiently? Contrasting perspectives and implications for policy. Energy Research \& Social Science, 7, 12-22. https://doi.org/10.1016/j. erss.2015.03.002.

Publisher's note Springer Nature remains neutral with regard to jurisdictional claims in published maps and institutional affiliations. 